\title{
Proximal Fibular Osteotomy vs high Tibial Osteotomy in medial compartment Osteoarthritis of knee
}

\author{
Sujay K Mahadik', Shriansh Pandey ${ }^{2}$, Neel S Belsare ${ }^{3}$, Girish S Shinde, \\ Shrikant B Deshpande ${ }^{5}$ \\ ${ }^{1,4}$ Assistant Professor, ${ }^{2,3}$ Junior Resident, ${ }^{5}$ Professor, Department Of Orthopedics, Bharati Vidyapeeth (Deemed to be \\ University) Medical College and Hospital, Sangli, Maharashtra, India
}

Background: Osteoarthritis of knee is one of the common conditions seen in older individuals and known to affect quality of life considerably. It makes it difficult for individuals with knee osteoarthritis to climb stairs, walk long distances, and stand for long time and squatting. In intractable cases not responding to conservative management surgical management such as proximal fibular Osteotomy (PFO) or high tibial Osteotomy (HTO) is routinely done. We conducted this comparative study to analyse the functional outcome of patients who had undergone HTO and PFO for medial compartment osteoarthritis of knee joint. Aims and Objectives: 1) To analyse the functional outcome of patients who had undergone HTO and PFO for medial compartment osteoarthritis of knee joint. 2) To compare complication rates in both the groups. Materials and Methods: A total of 60 patients with medial compartment knee osteoarthritis were included in this study on the basis of a predefined inclusion and exclusion criteria. Patients were randomized to 2 groups. Thirty patients undergoing proximal fibular osteotomy (Group A) and 30 patients undergoing high tibial osteotomy (Group B). The patients were followed up for improvements in functional outcome for 12 months. The statistical analysis was done using SSPS 21.0 software and $p$ value less than 0.05 were taken as statistically significant. Results: Mean time for surgery was less for PFO surgery as compared to HTO and the difference was statistically significant. Moreover mean bleeding amount, drainage volume and time required for full weight bearing was low in PFO group as compared to HTO group and the difference was found to be statistically significant $(P<0.05)$. The mean VAS score at the time of presentation in PFO and HTO groups was found to be $4.9+/-1.12$ and $4.7+/-1.02$ respectively. A statistically significant reduction in pain was documented at the time of follow up of 4 weeks in both the groups. The functional outcome and complication rates were comparable in both the groups. Conclusion: Proximal fibular osteotomy is a better option as compared to high tibial osteotomy in terms of mean surgery time, mean bleeding amount, drainage volume and time required for full weight bearing. Functional outcome and improvement in VAS were comparable in both the groups.

Key words: Knee osteoarthritis; proximal fibular Osteotomy; high tibial Osteotomy; functional outcome

\section{INTRODUCTION}

Osteoarthritis is one of the common types of disease compromising quality of life particularly in old age patients. ${ }^{1}$ With increasing life expectancy globally its prevalence is also increasing. Though there are multiple
Access this article online

Website:

http://nepjol.info/index.php/AJMS

DOI: 10.3126/ajms.v12i6.35673

E-ISSN: 2091-0576

P-ISSN: 2467-9100

Copyright (c) 2021 Asian Journal of Medical Sciences

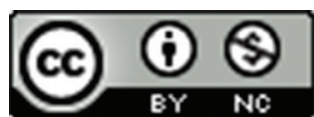

This work is licensed under a Creative Commons Attribution-NonCommercial 4.0 International License. 
Irrespective of etiology its manifestations are fairly uniform and consist of joint pain, reduced range of motion, crepitus and stiffness during rest. ${ }^{2}$ Osteoarthritis involving knee joint is common in individuals above 50 years of age and is one of the important causes of affected quality of life in older individuals. It makes it difficult for individuals with knee osteoarthritis to climb stairs, walk long distances, stand for long time and squatting (important from point of view of individuals from developing countries including India). ${ }^{3}$ The diagnosis of knee osteoarthritis is usually made on clinical examination and confirmed on the basis of imaging that include X-Ray, computed tomography or Magnetic resonance imaging of knee joint. ${ }^{4}$

The management of knee osteoarthritis depends upon the etiology. IN many cases lifestyle modification, NonSteroidal anti-inflammatory drugs and physiotherapy can significantly improve quality of life in patients with osteoarthritis. ${ }^{5}$ IN cases having specific etiology of osteoarthritis such as rheumatoid arthritis or psoriatic arthritis specific treatment including immunosuppressants, disease modifying agents and steroids may be required. Surgery is mainly reserved for patients having severe osteoarthritis not responding to medical management or in cases where it's hampering daily routine or significantly affecting quality of life. The surgical management mainly consists of arthroscopic procedures such as meniscectomy, chondroplasty, removal of loose body, synovectomy, and adhesiolysis. Arthroplastic surgeries such as total knee arthroplasty (TKA) and unicompartmental knee arthroplasty (UKA) are done in severe cases not responding to arthroscpic management. ${ }^{6}$ The other options for surgical management of osteoarthritis of knee joint severely affecting quality of life of affected individuals include Proximal fibular osteotomy (PFO) and high tibial osteotomy (HTO).?

Osteoarthritis of medial compartment of knee is the most common form of knee osteoarthritis seen in routine orthopedics practice. The 2 most common surgical procedures done for medial compartment knee osteoarthritis include high tibial osteotomy (HTO) and Proximal fibular osteotomy (PFO).Between these 2 procedures $\mathrm{PFO}$ is being increasingly done by various orthopedic surgeons and preferred over HTO due to simplicity of procedure, less expenses on surgical procedure and lesser need for rehabilitation as compared to HTO ${ }^{8}$

There is generally a lack of knowledge about PFO particularly in developing countries as this is a relatively new procedure. Moreover there is no extensive research comparing $\mathrm{HTO}$ and $\mathrm{PFO}$ in patients having osteoarthritis of medial compartment of knee joint. Therefore we conducted this comparative study to analyse the functional outcome of patients who had undergone $\mathrm{HTO}$ and $\mathrm{PFO}$ for medial compartment osteoarthritis of knee joint.

\section{MATERIALS AND METHODS}

A total of 60 patients with medial compartment knee osteoarthritis were included in this study on the basis of a predefined inclusion and exclusion criteria. The diagnosis of medial compartment of knee was made on the basis of history and clinical examination was confirmed on the basis of imaging including Load-position X-Ray film and computed tomography. In selected cases magnetic resonance imaging was done. Patients were randomized to 2 groups.

Group $A=30$ patients undergoing Proximal fibular osteotomy (PFO).

Group $B=30$ patients undergoing high tibial osteotomy (HTO).

All basic investigations include complete hemogram; Blood Grouping and Viral markers were carried out. If patients were aged more than 50 years both cardiologist and physician opinion were obtained to know cardiac and pulmonary reserve of the patient to withstand the surgical procedure. Informed written consent was obtained from all patients. Preoperative hemoglobin levels were determined and blood transfusion was given if indicated. All patients were electively posted after getting the Anesthetic fitness for surgery.

\section{SURGICAL PROCEDURE}

\section{Proximal fibular osteotomy}

All patients were operated under regional anesthesia. The patients were placed in supine position. An Osteotomy level i.e. $8 \mathrm{~cm}$ distal to the head of fibula was marked and a 5-6 cms skin incision over fibula was then taken through anterolateral approach. Blunt dissection was done and peroneus muscles were retracted posteriorly and shaft of the fibula was exposed. Care was taken not to damage the common peroneal nerve. A $2.5 \mathrm{~mm}$ drill bit was used to make multiple drill holes into the fibula at proximal and distal levels of the proposed Osteotomy and cuts were made using oscillating saw, $1 \mathrm{~cm}$ apart. Osteotomized fragment was removed and closure was done in layers. $\mathrm{C}$-arm was used pre and post operatively to evaluate the joint space.

\section{High tibial open wedge osteotomy}

All patients were operated under regional anesthesia. Patients were placed in supine position. Skin incision was 
taken from the insertion of the pes anserinus ascending $6-8 \mathrm{~cm}$ posterocranially. Pes tendons were retracted distally. Superficial fibers of the medial collateral ligament were carefully released and medial border of the patellar ligament was exposed. Level and direction of the Osteotomy were marked with two $2.3 \mathrm{~mm}$ guide wires aiming at the upper third of the proximal tibiofibular joint the wires end exactly at the lateral cortex. Length was measured using the wires and Osteotomy depth was marked on the saw blade. Biplanar Osteotomy was marked with electrocautery at an angle of $110^{\circ}$. Horizontal Osteotomy was done in the posterior $2 / 3$ of the tibia beneath the guide wires leaving a lateral bone bridge of $10 \mathrm{~mm}$ as a hinge. Complete anterior ascending Osteotomy was done at an angle of $110^{\circ}$. Osteotomy site was opened with the broad flat chisels. Osteotomy was spread and insertion of an arthrodesis spreader on the cortical surface of the posteromedial corner of the Osteotomy was done. Meticulous attention was paid to the tibial slope. Leg axis was evaluated clinically and radiographically in extension. Plate was inserted and proximal screws were locked. A temporary lag screw was then inserted into the first plate hole distal to the Osteotomy. Screws were then inserted into the remaining plate holes from distal to proximal after removing the distance holders. Lag screws were replaced by a bicortical locking screw. If the Osteotomy gap was found to be 13 $\mathrm{mm}$ or more, the gap was filled with autologous cancellous bone graft. Radiological documentation was done in both planes and wound closure was done.

The functional outcome was assessed using Japanese Orthopaedic Association score. Improvement in preoperative and postoperative VAS scores and incidence of complications such as neurovascular injuries, deep vein thrombosis, infections and recurrence were also compared in both the groups. The patients were followed up for improvements in functional outcome for 12 months. Follow up visits were scheduled at 1 month, 3 months, 6 months and 1 year. The statistical analysis was done using SSPS 21.0 software and p value less than 0.05 was taken as statistically significant.

\section{Inclusion criteria}

1. Patients with Medical Compartment Osteoarthritis of Knee not responding to medical management.

2. Those who gave informed written consent.

3. Age More than 18 years.

\section{Exclusion criteria}

1. Age less than 18 years

2. Those who refused consent.

3. Patients with active autoimmune disorders such as psoriatic arthritis, rheumatoid arthritis or systemic lupus erytheramatosus.
4. Pregnant females.

5. Patients having renal or hepatic failure, malignant diseases or any pathology likely to affect the assessment of functional outcome.

\section{RESULTS}

This was a comparative study of patients having osteoarthritis of knee and treated by either proximal fibular Osteotomy or high tibial open wedge Osteotomy. 60 patients were included in this study on the basis of inclusion and exclusion criteria. Out of the 30 patients in group A osteoarthritis was seen in 12 males and 18 females. In group $B$ there were 14 males and 16 females. The M:F ratio in group $A$ and $B$ was found to be 1:1.5 and 1:1.14 respectively. The gender distribution was comparable in both the groups with no statistically significant difference (Table 1).

The analysis of the age group of the patients showed that the most common affected age group in group A was found to be between 61-70 years (60\%) followed by $51-60$ years $(16.67 \%)$. Relatively less patients were present in the age group of $41-50$ years $(10 \%)$ and above 70 years of age $(13.33 \%)$. In group B most common affected age group was found to be between 51-60 years $(53.33 \%)$ followed by $61-70$ years $(36.67 \%)$. The mean age of affected cases in group $\mathrm{A}$ and $\mathrm{B}$ was found to be $60.33+/-7.74$ years and $57.8+/-6.06$ years respectively (Table 2).

Overweight and obesity was found to be one of the striking feature associated with patients with knee osteoarthritis. The analysis of BMI in patients of Group A showed that amongst 30 studied cases 11 (36.67\%) patients were obese

\begin{tabular}{lcc}
\multicolumn{3}{c}{ Table 1: Gender Distribution of the studied cases } \\
\hline & Males & Females \\
\hline Group A (PFO). & 12 & 18 \\
Group B (HTO) & 14 & 16 \\
\hline P (Two-tailed) $=0.794$ (Not Significant) &
\end{tabular}

$P($ Two-tailed $)=0.794$ (Not Significant)

\begin{tabular}{|c|c|c|c|c|}
\hline \multirow[t]{2}{*}{ Age } & \multicolumn{2}{|c|}{ Group A (PFO). } & \multicolumn{2}{|c|}{ Group B (HTO) } \\
\hline & $\begin{array}{l}\text { No of } \\
\text { cases }\end{array}$ & Percentage & $\begin{array}{l}\text { No of } \\
\text { cases }\end{array}$ & Percentage \\
\hline$</=40$ years & 0 & $0.00 \%$ & 0 & $0.00 \%$ \\
\hline $41-50$ years & 3 & $10.00 \%$ & 2 & $6.67 \%$ \\
\hline $51-60$ years & 5 & $16.67 \%$ & 16 & $53.33 \%$ \\
\hline $61-70$ years & 18 & $60.00 \%$ & 11 & $36.67 \%$ \\
\hline$>70$ years & 4 & $13.33 \%$ & 1 & $3.33 \%$ \\
\hline \multirow[t]{2}{*}{ Mean Age } & 60.33 & & $57.8+/-$ & \\
\hline & $+/-7.74$ & & 6.06 & \\
\hline
\end{tabular}


$(\mathrm{BMI}=/>30)$ and $9(30 \%)$ patients were overweight $(\mathrm{BMI}=\backslash>25$ but $<30)$. Rest of the patients had BMI less than 25. In Group B $22(73.33 \%)$ patients were either obese or overweight $(\mathrm{BMI}=>25)$ (Table 3$)$.

Mean duration of surgery in PFO and HTO group was found to be $42.6 \pm 11.2$ and $53.5 \pm 14.8$ minutes respectively. There was statistically significant difference in total duration required for surgery in two groups $(\mathrm{p}=0.0019)$. Mean bleeding amount was found to be 41.45 +/- $12.88 \mathrm{ml}$ and $71.8+/-22.62$ in PFO and HTO group respectively. The difference in mean bleeding amount was found to be statistically significant $(\mathrm{P}<0.0001)$. The drainage volume was also statistically significantly low in PFO group $(\mathrm{P}<0.0001)$. Mean time for full weight bearing was found to be $13.82+/-3.8$ hours in PFO group whereas this time was found to be $32.62+/-11.76$ hours in HTO group. The difference was found to be statistically significant $(\mathrm{P}<0.05)$.

At the time of presentation all patients were having moderate pain. The mean VAS score at the time of presentation in PFO and HTO groups was found to be $4.9+/-1.12$ and $4.7+/-1.02$ respectively (Table 4). A statistically significant reduction in pain was documented at the time of follow up of 4 weeks in both the groups.

The patients were followed up for improvements in functional outcome for 12 months. Follow up visits were scheduled at 1 month, 3 months, 6 months and 1 year. The functional outcome was assessed using Japanese orthopedic association score. Mean Japanese Orthopedic association (JOA) score at the time of presentation was found to be $61.6+/-12.2$ and $63.8+/-11.6$ in PFO and HTO group respectively. After completion of follow up at 1 year the Mean JOA score was found to be 88.4 $+/-16.2$ and $86.2+/-14.9$ respectively. The mean JOA scores at the time of 1 year follow up were found to be significantly improved as compared to JOA scores at the time of presentation and the difference was found to be highly significant (Table 5).

The cases were also analysed for complications such as infections, venous thrombosis, neurovascular injury and recurrence of deformity. In Group A infection and recurrence of deformity was seen in 1 patient $(3.33 \%)$ each. In Group B the out of 30 studied cases there were $2(6.66 \%)$ patients with infection, $2(6.66 \%)$ developed recurrence of deformity and venous thrombosis and neurovascular injury was seen in 1 patient $(3.33 \%)$ each. The complication rate was found to be comparable in both the groups with no statistically significant difference $(\mathrm{P}=0.2542)$ (Table 6).

\section{DISCUSSION}

This was a comparative study of 60 patients having osteoarthritis knee and treated by either proximal fibular Osteotomy or high tibial open wedge Osteotomy. In our study males were affected more commonly as compared to females although the difference was not found to be statistically significant $(\mathrm{P}>0.05)$. The $\mathrm{M}: \mathrm{F}$ ratio in group $\mathrm{A}$ and $\mathrm{B}$ was found to be 1:1.5 and 1:1.14 respectively. Various studies have reported that osteoarthritis is more common in females as compared to males. Particularly osteoarthritis involving knee and hand osteoarthritis is seen more commonly in females. Srikanth VK et al undertook a meta-analysis of population-based studies of OA providing sex-specific data. ${ }^{9}$ The authors found that

\begin{tabular}{|c|c|c|c|c|}
\hline \multirow[t]{2}{*}{ BMI } & \multicolumn{2}{|c|}{ Group A (PFO) } & \multicolumn{2}{|c|}{ Group B (HTO) } \\
\hline & $\begin{array}{l}\text { No of } \\
\text { cases }\end{array}$ & Percentage & $\begin{array}{l}\text { No of } \\
\text { cases }\end{array}$ & Percentage \\
\hline $\begin{array}{l}\text { Normal (Less } \\
\text { than 25) }\end{array}$ & 10 & $33.33 \%$ & 8 & $26.67 \%$ \\
\hline $\begin{array}{l}25-30 \\
\text { (Overweight) }\end{array}$ & 9 & $30.00 \%$ & 13 & $43.33 \%$ \\
\hline $\begin{array}{l}\text { More than } 30 \\
\text { (Obese) }\end{array}$ & 11 & $36.67 \%$ & 9 & $30.00 \%$ \\
\hline
\end{tabular}

\begin{tabular}{|c|c|c|c|}
\hline \multirow[t]{2}{*}{ Group } & \multicolumn{2}{|c|}{ Mean VAS Scores } & \multirow[t]{2}{*}{ P Value } \\
\hline & $\begin{array}{c}\text { AT } \\
\text { Presentation }\end{array}$ & $\begin{array}{c}\text { At Final } \\
\text { Follow up visit }\end{array}$ & \\
\hline Group A (PFO) & $4.9+/-1.12$ & $0.6 \pm 0.22$ & $<0.0001$ \\
\hline Group B (HTO) & $4.7+/-1.02$ & $0.92 \pm 0.34$ & $<0.0001$ \\
\hline
\end{tabular}

\begin{tabular}{lccc}
\multicolumn{3}{c}{ Table 5: Mean JOA Scores of the studied cases } \\
\cline { 2 - 3 } & \multicolumn{2}{c}{ Mean JOA Score } & P Value \\
\cline { 2 - 3 } & $\begin{array}{c}\text { At } \\
\text { Presentation }\end{array}$ & $\begin{array}{c}\text { At 1 year } \\
\text { Follow Up }\end{array}$ & \\
\hline Group A (PFO) & $61.6+/-12.2$ & $88.4+/-16.2$ & $\mathrm{P}<0.0001$ \\
Group B (HTO) & $63.8+/-11.6$ & $86.2+/-14.9$ & $\mathrm{P}<0.0001$ \\
\hline
\end{tabular}

\begin{tabular}{|c|c|c|c|c|}
\hline \multirow[t]{2}{*}{ Complications } & \multicolumn{2}{|c|}{ Group A (PFO). } & \multicolumn{2}{|c|}{ Group B (HTO) } \\
\hline & $\begin{array}{l}\text { No of } \\
\text { cases }\end{array}$ & Percentage & $\begin{array}{l}\text { No of } \\
\text { cases }\end{array}$ & Percentage \\
\hline Infection & 1 & $3.33 \%$ & 2 & $6.66 \%$ \\
\hline $\begin{array}{l}\text { Venous } \\
\text { thrombosis }\end{array}$ & 0 & $0.00 \%$ & 1 & $3.33 \%$ \\
\hline $\begin{array}{l}\text { Neurovascular } \\
\text { injury }\end{array}$ & 0 & $0.00 \%$ & 1 & $3.33 \%$ \\
\hline $\begin{array}{l}\text { Recurrence of } \\
\text { deformity }\end{array}$ & 1 & $60.00 \%$ & 2 & $6.66 \%$ \\
\hline
\end{tabular}


Males had a reduced risk for prevalent knee osteoarthritis [and hand but not for other sites. Males less than 55 years of age were found to have a greater risk of prevalent cervical spine osteoarthritis. Males also had significantly reduced rates of incident $\mathrm{OA}$ in the knee and hip with a trend for hand. Females, particularly those above 55 years, found to have more severe osteoarthritis in the knee but not other sites. The authors concluded that females tend to have more severe knee osteoarthritis, particularly after menopausal age. Similar predominant female affection was also reported by Quintana JM et al., ${ }^{10}$ and Pal CP et al. ${ }^{11}$

Individuls above 55 years were found to be commonly affected by osteoarthritis in our study. The mean age of affected cases in group $A$ and $B$ was found to be 60.33 $+/-7.74$ years and $57.8+/-6.06$ years respectively. Losina $\mathrm{E}$ et al., conducted a study to estimate the incidence and lifetime risk of diagnosed symptomatic knee osteoarthritis $(\mathrm{OA})$ based on self-reports in the US population. ${ }^{12}$ The authors found that estimated incidence of diagnosed symptomatic knee $\mathrm{OA}$ was highest among adults ages 55-64 years, ranging from $0.37 \%$ per year for nonobese men to $1.02 \%$ per year for obese women. The estimated median age at knee OA diagnosis was 55 years. The estimated lifetime risk was $13.83 \%$, ranging from $9.60 \%$ for nonobese men to $23.87 \%$ in obese women. The median age of 55 years was comparable to cases in our study. Similar age distribution was also reported by Heidari B et al., ${ }^{13}$ and Kuptniratsaikul V et al. ${ }^{14}$

The analysis of BMI in patients of Group A showed that amongst 30 studied cases $11(36.67 \%)$ patients were obese $(\mathrm{BMI}=/>30)$ and $9(30 \%)$ patients were overweight $(\mathrm{BMI}=\backslash>25$ but $<30)$. Rest of the patients had BMI less than 25. In Group B 22 (73.33\%) patients were either obese or overweight (BMI $=>25)$. Obesity is known to accelerate the process of osteoarthritis. Coggon D et al conducted a study to assess the risk of knee osteoarthritis (OA) attributable to obesity. In this study authors found that relative to a body mass index (BMI) of $24.0-24.9 \mathrm{~kg} / \mathrm{m}^{2}$, the risk of knee OA increased progressively from $0.1(95 \%$ CI $0.0-0.5)$ for a $\mathrm{BMI}<20 \mathrm{~kg} / \mathrm{m}^{2}$ to $13.6(95 \%$ CI $5.1-36.2)$ for a BMI of $36 \mathrm{~kg} / \mathrm{m}^{2}$ or higher. ${ }^{15}$ The authors concluded that if all overweight and obese people reduced their weight by $5 \mathrm{~kg}$ or until their BMI was within the recommended normal range, $24 \%$ of surgical cases of knee OA ( $95 \%$ CI $19-27 \%$ ) might be avoided. Similar connection between BMI and osteoarthritis was also reported by the authors such as Raud, B et al., ${ }^{16}$ and Powell A et al. ${ }^{17}$

PFO and HTO both are the common procedures done for patients with osteoarthritis not responding to conservative management including physiotherapy. The comparison of both time required for these 2 procedures showed that time for surgery was less for PFO surgery as compared to HTO and the difference was statistically significant. Moreover mean bleeding amount, drainage volume and time required for full weight bearing was low in $\mathrm{PFO}$ group as compared to HTO group and the difference was found to be statistically significant $(\mathrm{P}<0.05)$. The mean VAS score at the time of presentation in PFO and HTO groups was found to be $4.9+/-1.12$ and $4.7+/-1.02$ respectively. A statistically significant reduction in pain was documented at the time of follow up of 4 weeks in both the groups. Both groups were found to have a statitistically significant improvement in functional outcome as assesed bu JOA scores at presentation and at follow up. The complication rate was found to be comparable in both the groups with no statistically significant difference $(\mathrm{P}=0.2542)$.

Zou $G$ et al., reported conducted a study to to investigate the early clinical effect of proximal fibular osteotomy on varus Knee Osteoarthritis (KOA), operation time, bleeding amount during operation and drainage volume after operation significantly decreased while the full weightbearing time significantly shortened in the PFO group as compared with the HTO group $(\mathrm{p}<0.05) .{ }^{18}$ The pain VAS and femur-tibial angle significantly decreased and the JOA score of the knee joint significantly increased in the PFO group as compared with the HTO $(\mathrm{p}<0.05)$. A significantly lower incidence of complications, including neurovascular injury, deep infection, lower-limb deep vein thrombosis, fracture, delayed union and deformity recurrence, was found in the PFO group compared with the control group $(p<0.05)$. Similar results were also reported by the authors such as Yang ZY et al., ${ }^{19}$ and Sprenger TR et al. ${ }^{20}$

\section{CONCLUSION}

Proximal Fibular Osteotomy is found to have reduced mean surgery time, mean bleeding amount and time required for full weight bearing as compared to high tibial Osteotomy making it a better choice for managing intractable knee osteoarthritis cases. Both these procedures were found to have significant reduction in Pain, functional improvement and complication rates.

\section{REFERENCES}

1. Farr li J, Miller LE and Block JE. Quality of life in patients with knee osteoarthritis: a commentary on nonsurgical and surgical treatments. Open Orthop J. 2013; 7:619-623.

https://doi.org/10.2174/1874325001307010619

2. Hunter DJ, McDougall JJ and Keefe FJ. The symptoms of osteoarthritis and the genesis of pain. Rheum Dis Clin North Am. 2008; 34(3):623-643.

https://doi.org/10.1016/j.rdc.2008.05.004

3. Kim JM and Moon MS. Squatting following total knee arthroplasty. 
Clin Orthop Relat Res. 1995; (313):177-186. PMID: 7641477.

4. Hayashi D, Roemer FW and Guermazi A. Imaging of osteoarthritis-recent research developments and future perspective. Br J Radiol. 2018; 91(1085): 20170349. https://doi.org/10.1259/bjr.20170349

5. da Costa BR, Reichenbach S, Keller N, Nartey L, Wandel S, Jüni $P$, et al. Effectiveness of non-steroidal anti-inflammatory drugs for the treatment of pain in knee and hip osteoarthritis: a network meta-analysis. Lancet. 2017; 390(10090):e21-e33. https://doi.org/10.1016/S0140-6736(17)31744-0

6. Katz JN, Earp BE and Gomoll AH. Surgical management of osteoarthritis. Arthritis Care Res (Hoboken). 2010; 62(9):1220-1228. https://doi.org/10.1002/acr.20231

7. Vaish A, Kumar Kathiriya Y and Vaishya R. A Critical Review of Proximal Fibular Osteotomy for Knee Osteoarthritis. Arch Bone Jt Surg. 2019; 7(5):453-462.

8. Huang $\mathrm{H}$, Huang $\mathrm{S}$, Liang $\mathrm{G}$, Zeng L, Pan J, Yang $\mathrm{W}$, et al. Is high tibial osteotomy better than proximal fibula osteotomy for treating knee osteoarthritis? A protocol for a systematic review and meta-analysis of clinical controlled trials. Medicine (Baltimore). 2020; 99(4):e18910.

\section{https://doi.org/10.1097/MD.0000000000018910}

9. Srikanth VK, Fryer JL, Zhai G, Winzenberg TM, Hosmer D and Jones G. A meta-analysis of sex differences prevalence, incidence and severity of osteoarthritis. Osteoarthritis Cartilage. 2005; 13(9):769-781.

https://doi.org/10.1016/j.joca.2005.04.014

10. Quintana JM, Arostegui I, Escobar A, Azkarate J, Goenaga J and Lafuente I. Prevalence of knee and hip osteoarthritis and the appropriateness of joint replacement in an older population. Arch Intern Med. 2008; 168(14):1576-1584. https://doi.org/10.1001/archinte.168.14.1576

11. Pal CP, Singh P, Chaturvedi S, Pruthi KK and Vij A. Epidemiology of knee osteoarthritis in India and related factors. Indian J Orthop. 2016; 50(5):518-522.

https://doi.org/10.4103/0019-5413.189608
12. Losina E, Weinstein AM, Reichmann WM, Burbine SA Solomon DH, Daigle ME, et al. Lifetime risk and age at diagnosis of symptomatic knee osteoarthritis in the US. Arthritis Care Res (Hoboken). 2013; 65(5):703-711. https://doi.org/10.1002/acr.21898

13. Heidari B. Knee osteoarthritis prevalence, risk factors, pathogenesis and features: Part I. Caspian J Intern Med. 2011; 2(2):205-212.

14. Kuptniratsaikul V, Tosayanonda O, Nilganuwong $S$ and Thamalikitkul V. The epidemiology of osteoarthritis of the knee in elderly patients living an urban area of Bangkok. J Med Assoc Thai. 2002; 85(2):154-161.

15. Coggon D, Reading I, Croft P, McLaren M, Bett D and Cooper C. Knee osteoarthritis and obesity. Int J Obes. 2001; 25: 622-627. https://doi.org/10.1038/sj.ijo.0801585

16. Raud B, Gay C, Guiguet-Auclair C, Bonnin A, Gerbaud L, Pereira $B$, et al. Level of obesity is directly associated with the clinical and functional consequences of knee osteoarthritis. Sci Rep. 2020; 10: 3601. https://doi.org/10.1038/s41598-020-60587-1

17. Powell A, Teichtahl AJ, Wluka AE and Cicuttini FM. Obesity: a preventable risk factor for large joint osteoarthritis which may act through biomechanical factors. Br J Sports Med. 2005; 39:4-5. https://doi.org/10.1136/bjsm.2004.011841

18. Zou G, Lan W, Zeng Y, Xie J, Chen S and Qiu Y. Early clinical effect of proximal fibular osteotomy on knee osteoarthritis. Biomed Res. 2017; 28(21):9291-9294.

19. Yang ZY, Chen W, Li CX, Wang J and Shao DC. Medial compartment decompression by fibular osteotomy to treat medial compartment knee osteoarthritis: a pilot study. Orthopedics. 2015; 38: 1110-1114. https://doi.org/10.3928/01477447-20151120-08

20. Sprenger TR and Doerzbacher JF. Tibial osteotomy for the treatment of varus gonarthrosis. Survival and failure analysis to twenty-two years. J Bone Joint Surg Am. 2003; 85-A: 469-474. https://doi.org/10.2106/00004623-200303000-00011

\footnotetext{
Author's contribution:

SM- Concept and design of the study; interpreted the results, prepared first draft of manuscript and critical revision of the manuscript; SP- Statistically analysedand interpreted; reviewed the literature and manuscript preparation; NB and GS- Design of the study, statistically analysed and interpreted, preparation of manuscript and revision of the manuscript; SD- Concept and coordination of the overall study.

Work attributed to:

Department Of Orthopedics Bharati Vidyapeeth (Deemed to be University) Medical College and Hospital, Sangli, Maharashtra, India.

Orcid ID

Dr. Sujay Mahadik- (1) https://orcid.org/0000-0002-9134-6423

Dr. Shariansh Pandey- (1) https://orcid.org/0000-0002-5498-4004

Dr. Shrikant Deshpande- (1) https://orcid.org/0000-0002-2880-8891

Source of Funding: None, Conflict of Interest: None.
} 